\title{
Aqueous-phase tandem catalytic conversion of xylose to furfuryl alcohol over [Al]-SBA-15 molecular sieves
}

DOI:

10.1039/C9CY01235D

\section{Document Version}

Accepted author manuscript

Link to publication record in Manchester Research Explorer

\section{Citation for published version (APA):}

Perez, R. F., Albuquerque, E. M., Borges, L. E. P., Hardacre, C., \& Fraga, M. A. (2019). Aqueous-phase tandem catalytic conversion of xylose to furfuryl alcohol over [Al]-SBA-15 molecular sieves. Catalysis Science \&

Technology. https://doi.org/10.1039/C9CY01235D

\section{Published in:}

Catalysis Science \& Technology

\section{Citing this paper}

Please note that where the full-text provided on Manchester Research Explorer is the Author Accepted Manuscript or Proof version this may differ from the final Published version. If citing, it is advised that you check and use the publisher's definitive version.

\section{General rights}

Copyright and moral rights for the publications made accessible in the Research Explorer are retained by the authors and/or other copyright owners and it is a condition of accessing publications that users recognise and abide by the legal requirements associated with these rights.

\section{Takedown policy}

If you believe that this document breaches copyright please refer to the University of Manchester's Takedown Procedures [http://man.ac.uk/04Y6Bo] or contact uml.scholarlycommunications@manchester.ac.uk providing relevant details, so we can investigate your claim.

\section{OPEN ACCESS}






\section{Accepted Manuscript}

This article can be cited before page numbers have been issued, to do this please use: R. F. Perez, E. M. Albuquerque, L. E. P. Borges, C. Hardacre and M. A. Fraga, Catal. Sci. Technol., 2019, DOI:

\section{Catalysis Science \& Technology}



This is an Accepted Manuscript, which has been through the Royal Society of Chemistry peer review process and has been accepted for publication.

Accepted Manuscripts are published online shortly after acceptance, before technical editing, formatting and proof reading. Using this free service, authors can make their results available to the community, in citable form, before we publish the edited article. We will replace this Accepted Manuscript with the edited and formatted Advance Article as soon as it is available.

You can find more information about Accepted Manuscripts in the Information for Authors.

Please note that technical editing may introduce minor changes to the text and/or graphics, which may alter content. The journal's standard Terms \& Conditions and the Ethical guidelines still apply. In no event shall the Royal Society of Chemistry be held responsible for any errors or omissions in this Accepted Manuscript or any consequences arising from the use of any information it contains. 


\title{
Journal Name
}

\section{Aqueous-phase tandem catalytic conversion of xylose to furfuryl alcohol over [AI]-SBA-15 molecular sieves}

Received 00th January 20xx Accepted 00th January 20xx

DOI: $10.1039 / \times 0 x \times 00000 x$

www.rsc.org/

\author{
Rafael F. Perez, ${ }^{a, b}$ Elise M. Albuquerque, ${ }^{b}$ Luiz E. P. Borges, ${ }^{a}$ Christopher Hardacre ${ }^{c}$ and Marco A. \\ Fraga*a,b
}

\begin{abstract}
Catalytic active sites were controllably assembled into SBA-15 framework by direct hydrothermal synthesis. Incorporation of $\mathrm{Al}$ as a heteroatom at different $\mathrm{Si} / \mathrm{Al}$ ratios was used to tune their surface properties and the catalysts were characterized by SAXRD, ICP-OES, FE-SEM, TEM, FTIR, ${ }^{29} \mathrm{Si}$ and ${ }^{27} \mathrm{Al}$ CP-NMR, pyridine adsorption and titration in water. Reactivity towards direct conversion of xylose to furfuryl alcohol was systematically investigated. Brønsted acid sites, generated by introducing Al into the siliceous SBA-15 framework, were found to be active for pentose dehydration reaction, whilst the Lewis acid sites promoted the transfer hydrogenation of adsorbed furfural intermediate to furfuryl alcohol. A remarkably high selectivity to furfuryl alcohol $(90-95 \%)$ was observed using the mesoporous catalysts and it was dependent of the Al concentration in the siliceous framework. The vicinity of Brønsted and Lewis acid sites is suggested to be of major concern since the adsorbed furfural species is proposed to be reduced to furfuryl alcohol without being desorbed. The [AI]-SBA-15 molecular sieves were shown to be chemically and structurally stable demonstrating good recyclability in the aqueous-phase upgrading of xylose.
\end{abstract}

\section{Introduction}

Lignocellulosic biomass has been increasingly explored as a renewable feedstock for sustainable reactions because of its ton-scale availability and the pursuit of the chemical sector to decrease the use of conventional fossil-based sources. Such an interest can indeed play a fundamental role in the establishment of the bio-economy allowing the alternative production of green chemicals and specialties in current operating agroindustrial sites.

Another strategic advantage of lignocellulosic biomass is its chemical composition, since it is essentially made of three major carbon sources - lignin, cellulose and hemicellulose. The latter two fractions are polysaccharides, which account for up to $80 \%$ of all biomass. These biopolymers can be hydrolysed to C6 and C5 monosaccharides and then upgraded to industrially target chemicals.

Furthermore, xylose, released from hemicellulose, has long been used to produce furfural, ${ }^{1-3}$ which is an aromatic aldehyde that has been recognized as a platform molecule

a. Instituto Militar de Engenharia, Praça Gen. Tibúrcio, 80, Urca, Rio de Janeiro/RJ, 22290-270, Brazil.

b. Instituto Nacional de Tecnologia/MCTIC, Laboratório de Catálise, Av. Venezuela 82/518, Saúde, Rio de Janeiro/RJ, 20081-312, Brazil. marco.fraga@int.gov.br

C School of Chemical Engineering and Analytical Science, The University of

Manchester, The Mill, Sackville Street, Manchester M13 9PL, UK.

c.hardacre@manchester.ac.uk

† Footnotes relating to the title and/or authors should appear here.

Electronic Supplementary Information (ESI) available: [details of any supplementary information available should be included here]. See DOI: $10.1039 / x 0 x x 00000 x$ since it can lead to the production of a wide variety of other chemicals. ${ }^{2,3}$ In addition, furfuryl alcohol, tetrahydrofuran, methylfuran and $\gamma$-valerolactone have been identified as high value-added chemicals which can be derived from furfural. In each case the biomass conversion relies on a multi-step, multicatalyst process within which xylose is the primary feedstock. Cascade reactions involving initial xylose dehydration and furfural selective hydrogenation or hydrogenolysis are the established routes in this case.

In the case of xylose dehydration, significant efforts have been made to increase the sustainable aspect of this reaction, particularly by replacing the conventionally used homogeneous stoichiometric mineral acids with heterogeneous catalysts. ${ }^{4-12}$ Moreover the hydrogenation of furfural to furfuryl alcohol in a second independent process is industrially carried out over CuCr-based catalyst which is unsustainable. ${ }^{13,14}$ To date, this catalytic system remains despite extensive studies aimed at replacing it for base or noble metals supported catalytic processes. . $^{3,15-19}$

Recently, a number of different approaches for a novel integrated process have been reported in which the cascade reactions occur either in a double catalytic bed tubular reactor ${ }^{20}$ or using multifunctional catalysts which lead to the tandem reactions over acid and noble metal sites in a batch reactor. ${ }^{21-23}$ Although furfuryl alcohol yields of up to $90 \%$ were reported, these approaches used high hydrogen pressures (> $30 \mathrm{bar}$ ) to reduce the furfural carbonyl bond on a metal-based catalyst. Alternatively, a one-pot chemo-enzymatic sequential dehydration and bioreduction process has also been proposed. In this hybrid process a biocompatible solid acid catalyst and 
resting cells of E. coli CCZU-A13 led to $44 \%$ yield of furfuryl alcohol. ${ }^{24}$ Despite the positive result, the furfuryl alcohol productivity was not high enough to enable it to be practically applied.

To overcome these limitations within an industrial process, a hydrogen-free process relying on transfer hydrogenation using alcohols as $\mathrm{H}$-donors has been proposed. This has the advantages that, it is a highly selective reaction towards carbonyl reduction, ${ }^{25}$ preserving thus the carbon double bonds in the furanic ring. In addition, this reaction can be promoted by several heterogeneous recyclable catalysts, opening the opportunity to be more economically feasible. ${ }^{26}$

Despite the efforts in exploiting transfer hydrogenation for biomass conversion, the studies, to date, have largely been focused on saccharides derivatives such as furfural, 27-36 hydroxymethylfurfural ${ }^{37-39}$ or levulinic acid and alkyl levulinates. ${ }^{40-43}$ One-pot tandem catalytic conversion of xylose, on the other hand, has not been studied extensively. ${ }^{29,44-47}$ In all cases, despite dealing with different target end products, these studies focused on the use of $\mathrm{MFI}^{45,47} \mathrm{BEA}, 29,44,45$ or FAU 45,46 topology zeolites.

Furthermore, the direct synthesis of furfuryl alcohol from xylose via tandem dehydration-transfer hydrogenation reactions based on the Meerwein-Ponndorf-Verley (MPV) reduction has only very recently investigated. ${ }^{45}$ In this case, 2propanol was used as sacrificing alcohol allowing the intramolecular hydride transfer on Lewis acid sites while the Brønsted sites were responsible for the xylose dehydration. Nevertheless, it was shown that some zeolite structures limit the xylose accessibility to the intraporous surface centres due to the narrow microporous zeolites with a MFI framework topology. ${ }^{45}$ Therefore, the use of a larger accessible mesostructure may be an alternative. However, the low acidity of such non-zeolitic structures, the low- or non-crystallinity of mesoporous molecular sieves and the low structural stability of some of these mesoporous families impose critical obstacles in their effective use for biomass-derived saccharide aqueousphase processing. In addition, siliceous M41S or SBA- $n$ mesoporous materials exhibit limited catalytic activity which also limits their applicability in catalytic transfer hydrogenation for biomass upgrading. ${ }^{27,40,48}$

In this contribution, catalytic active sites were controllably assembled within a SBA-15 framework by direct hydrothermal synthesis. Incorporation of Al as a heteroatom at different $\mathrm{Si} / \mathrm{Al}$ ratios as a way to tune surface properties and reactivity to the direct conversion of xylose to furfuryl alcohol was also systematically investigated. This direct use of a monosaccharide has advantages in that it may eradicate multiple separations of chemical intermediates and reaction stages leading to an overall process cost reduction. Therefore, special attention was given to these metal-free molecular sieve catalysts reusability and structural stability in the molecular hydrogen-free aqueous-phase process.

\section{Experimental}

Synthesis of SBA-15 and isomorphically substituted SBA-15
Siliceous SBA-15 was synthesized through a procedure adaated

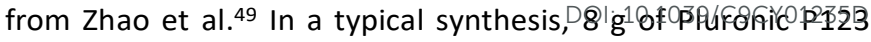
(molecular weight $=5,800 \mathrm{~g} \mathrm{~mol}^{-1}-\mathrm{EO}_{20} \mathrm{PO}_{70} \mathrm{EO}_{20}$, SigmaAldrich) was dissolved in $200 \mathrm{~mL}$ of $\mathrm{HCl} 2 \mathrm{~mol} \mathrm{~L}^{-1}$ solution, followed by the direct dropwise addition of $18.4 \mathrm{~mL}$ of tetraethylorthosilicate (TEOS, Sigma-Aldrich). The solution was magnetically stirred for $20 \mathrm{~h}$ at $35{ }^{\circ} \mathrm{C}$. The mixture was then hydrothermally treated at $100{ }^{\circ} \mathrm{C}$ for $24 \mathrm{~h}$ in a $300 \mathrm{~mL}$ Teflonlined stainless steel autoclave. The white powder formed was filtered and washed with $2 \mathrm{~L}$ of deionized water and dried overnight at $60{ }^{\circ} \mathrm{C}$, and finally calcined at $500{ }^{\circ} \mathrm{C}$ for $5 \mathrm{~h}$ at a heating rate of $1^{\circ} \mathrm{C} \mathrm{min}^{-1}$ and under synthetic air flow of $50 \mathrm{~mL}$ $\min ^{-1}$.

To prepare the [Al]-SBA-15 samples, $8 \mathrm{~g}$ of Pluronic 123 (Sigma-Aldrich) were dissolved in $200 \mathrm{~mL}$ of $\mathrm{HCl} 2 \mathrm{~mol} \mathrm{~L}^{-1}$ solution along with aluminium isopropoxide $\left(\mathrm{Al}(\mathrm{iPrO})_{3}\right.$, SigmaAldrich). The amount of the aluminium precursor was adjusted so as to obtain the desired Si/Al ratio. After $10 \mathrm{~min}$. TEOS (18.4 $\mathrm{mL}$ ) was added dropwise, followed by stirring for $20 \mathrm{~h}$ at $35^{\circ} \mathrm{C}$. Thereafter, the same procedure used to synthesise the siliceous SBA-15 sample was used. The samples were named as [Al]-SBA-15 $(\mathrm{Si} / \mathrm{Al}=\mathrm{X})$, where $\mathrm{X}$ is the experimental Si/Al ratio.

\section{Physicochemical characterization of synthesized catalysts}

The porosity of the catalysts was characterized by nitrogen adsorption-desorption isotherms collected at $-196{ }^{\circ} \mathrm{C}$ using a Micromeritics ASAP 2020 equipment. Prior to analyses, the samples were degassed at $350{ }^{\circ} \mathrm{C}$. Specific surface areas were determined according to the Brunauer-Emmet-Teller (BET) isothermal equation while pore size distribution and the average pore size were calculated by Barrett-Joyner-Halenda (BJH) method with KJS correction. The desorption branch was used.

Structural long-range order was evaluated through smallangle X-ray powder diffraction (SAXRD) performed in a Bruker D8 Advance diffractometer equipped with a Lynx-eye position sensitive detector and using $\mathrm{CuK} \alpha$ radiation. Analyses parameters were set with an angular range of $0.5-5^{\circ} 2 \theta$ scanned at $0.6^{\circ} \mathrm{min}^{-1}$.

The short-range order of silica framework was assessed by Fourier transformed infrared spectroscopy (FTIR). The spectra were collected from 4000 to $400 \mathrm{~cm}^{-1}$ on a Nicolet 6700 Thermo Scientific spectrometer in $\mathrm{KBr}$ wafers with a resolution of $4 \mathrm{~cm}^{-1}$ and accumulated over 32 scans.

The $\mathrm{Si}$ and $\mathrm{Al}$ chemical environments were examined by ${ }^{29} \mathrm{Si}$ and ${ }^{27} \mathrm{Al}$ solid state crossed polarization nuclear magnetic resonance (CP-NMR). ${ }^{29} \mathrm{Si} \mathrm{CP}-\mathrm{NMR}$ spectra were collected in a Bruker 400 Avance II+ spectrometer at a frequency of 79.4 $\mathrm{MHz}$, pulse length of $6 \mu \mathrm{s}$ and repetition time of $60 \mathrm{~s}$. As for ${ }^{27} \mathrm{Al} \mathrm{CP}-\mathrm{NMR}$, spectra were recorded at $104.3 \mathrm{MHz}$, pulse length of $1 \mathrm{~ms}$ and repetition time of $0.5 \mathrm{~s}$.

Chemical composition was assessed by determining $\mathrm{Al}$ and Si content in synthesized catalysts using inductively coupled plasma - optical emission spectrometry (ICP-OES). Samples were firstly calcined at $900{ }^{\circ} \mathrm{C}$ for $6 \mathrm{~h}$ at a heating rate of $10^{\circ} \mathrm{C}$ $\mathrm{min}^{-1}$. After, they were dissolved in $\mathrm{HNO}_{3}$ and $\mathrm{HF}$ with the aid 
of an Ethos 1 (Milestone S.r.I.) digestor. The resulting solution was diluted prior to the measurements in the spectrometer. A Varian Vista MXP spectrometer was used for these measurements. All solutions were analysed in triplicate and presented a standard deviation $<5 \%$.

The morphology of the samples was examined by field emission scanning electron microscopy (FE-SEM) in a Quanta FEG $450 \mathrm{FEI}$ microscope operating with an accelerating voltage of $20 \mathrm{kV}$. Metal stubs covered with carbon film were used to deposit the samples, which were subsequently sputter coated with platinum.

All samples were also examined by transmission electron microscopy (TEM) using a Jeol JEM-2100F microscope, with an acceleration voltage of $200 \mathrm{kV}$. The powders were firstly suspended in 2-propanol and then deposited over a carboncoated copper grid ( $5 \mathrm{~nm}$ ).

Acid surface sites were determined by pyridine adsorption Fourier transformed infrared transmittance spectroscopy (PyFTIR). ${ }^{50}$ The catalysts were analysed as self-supported wafers of $12 \mathrm{~mm}$ diameter held in a glass cell bearing $\mathrm{CaF}_{2}$ windows. Prior to the analyses, the samples were submitted to a thermal pre-treatment at $500{ }^{\circ} \mathrm{C}$ for $1 \mathrm{~h}$ under high vacuum. Thereafter, the samples were cooled down to room temperature and a background spectrum was collected. Wafers were then exposed to 10 Torr of pyridine at $25^{\circ} \mathrm{C}$ for 30 min., degassed and the first spectrum was taken. Subsequent spectra were measured along as function of temperature up to $350{ }^{\circ} \mathrm{C}$ following the pyridine thermal desorption. It should be noted, however, that all spectra were collected at room temperature since the samples were cooled down after each thermal desorption step. A Nicolet iS50 spectrometer was used and the spectra were measured between $4000-400 \mathrm{~cm}^{-1}$ at a resolution of $4 \mathrm{~cm}^{-1}$.

The total acidity was determined by titration of the catalysts as a suspension in water. ${ }^{51} 10 \mathrm{mg}$ of the catalysts were sonicated in $15 \mathrm{~mL}$ of $\mathrm{NaOH} 0.01 \mathrm{~mol} \mathrm{~L}^{-1}$ solution for 10 min. Then, the samples were titrated against $\mathrm{HCl} 0.01 \mathrm{~mol} \mathrm{~L}^{-1}$ solution until a pH 7.0 was reached. The measurements were made in triplicate using a pHmeter Inolab WTW level1 with a combined glass electrode.

\section{Catalytic activity}

The catalytic performance was evaluated in a semi-batch Parr reactor. In each run, $80 \mathrm{~mL}$ of a $83 \mathrm{mmol} \mathrm{L}^{-1}$ xylose solution in monophasic water:2-propanol (1:1) was poured into the reactor with $0.25 \mathrm{~g}$ of the catalyst. In all cases, the temperature was kept at $130{ }^{\circ} \mathrm{C}$ and the pressure was set to 30 bar with $\mathrm{N}_{2}$ with a stirrer speed of $600 \mathrm{rpm}$ following the conditions established in our previous work. ${ }^{21-23}$ These conditions were shown to avoid diffusional limitations and contribution from xylose thermoconversion. Samples were taken periodically up to $6 \mathrm{~h}$ and analysed by high performance liquid chromatography (HPLC) to evaluate the sugar conversion ( $\left.\mathrm{X}_{\text {pentose }}\right)$ and products distribution. The selectivity
(S) is presented on a molar basis taking into accoumnt the consumption of pentoses.

DOI: $10.1039 /$ C9CY01235D

\section{Xpentose $(\%)=\left([\text { pentose }]_{i}-[\text { pentose }]_{f}\right) /[\text { pentose }]_{i} \times 100$}

$S(\%)=[$ product $] /\left([\text { pentose }]_{i}-[\text { pentose }]_{f}\right) \times 100$

where:

[pentose $_{\mathrm{i}}=\left[\right.$ xylose $_{\mathrm{i}}$

[pentose $_{f}=[\text { xylose }]_{f}+[\text { xylulose }]_{f}$

HPLC analyses were performed using a Waters Alliance e2695 liquid chromatograph coupled to a photodiode array detector 2998 (PDA) and a refractive index detector 2414 (RID) set at $50{ }^{\circ} \mathrm{C}$. An aqueous solution of $\mathrm{H}_{2} \mathrm{SO}_{4}$ at $5 \mathrm{mmol} \mathrm{L}^{-1}$ was used as mobile phase $\left(0.7 \mathrm{~mL} \mathrm{~min}^{-1}\right)$ in isocratic mode in a Biorad Aminex HPX-87H ion exchange column set at $65^{\circ} \mathrm{C} . .^{21-23}$

After the reaction the catalysts were recovered by filtration, washed with water, dried at $100{ }^{\circ} \mathrm{C}$ overnight and then used again in another catalytic run carried out under the exact same conditions. Three consecutive runs were performed to investigate catalyst deactivation.

\section{Post-reaction analyses}

The spent catalysts were also examined by SAXRD, TEM, ${ }^{27} \mathrm{AI}$ CP-NMR and ICP-OES in order to evaluate the structural and chemical stability. These analyses followed the same experimental procedures described previously for the fresh samples.

\section{Results and discussion}

The structure of synthesized catalysts was monitored by SAXRD. The diffraction patterns (Fig. S1) presented three wellresolved peaks, corresponding to the (100), (110) and (200) indexed planes at $2 \theta 0.7^{\circ}, 1.3^{\circ}$ and $1.5^{\circ}$, which revealed that the ordered two-dimensional hexagonal $(\mathrm{P} 6 \mathrm{~mm})$ structure of SBA-15 was successfully obtained for all catalysts, irrespective of their chemical composition. ICP-OES analyses allowed determining the exact $\mathrm{Al}$ content in each sample as collected in Table 1.

Their porosity was analysed by collecting $\mathrm{N}_{2}$ adsorption/desorption isotherms (Fig. S2). It was seen that the isotherms are type IVa holding H1-type hysteresis, 52 which is consistent with one-dimensional cylindrical large-pore channels expected for SBA-15 type solids. Surface area $\left(\mathrm{S}_{\mathrm{BET}}\right)$, pore volume $\left(\mathrm{V}_{p}\right)$ and average pore diameter $\left(\phi_{p}\right)$ data are summarized in Table 1 are in line with previous reports for similar materials. ${ }^{53-56}$ As expected, the average pore diameter increased systematically with addition of Al in the framework, which is related to the larger ionic radius of Al compared to that of Si. ${ }^{53-56}$ 
Table 1. Surface area $\left(\mathrm{S}_{\mathrm{BET}}\right)$, pore volume $\left(\mathrm{V}_{p}\right)$, average pore diameter $\left(\phi_{p}\right)$, Al content $(\% A l)$, concentration of Lewis (LAS) and Brønsted (BAS) acid sites, and total acidity $\left(\mathrm{H}^{+}\right)$of all synthesized SBA-15 catalysts and their areal initial reaction rate $\left(\mathrm{r}_{0}\right)$ on aqueourspphase $\times$ (xylose conversion. Reaction conditions: $130{ }^{\circ} \mathrm{C}, 30$ bar $\left(\mathrm{N}_{2}\right)$, water:2-propanol 1:1, xylose solution at $83 \mathrm{mmol} \mathrm{L}^{-1}$.

\begin{tabular}{lllllllll}
\hline Catalyst & $\begin{array}{l}\mathrm{S}_{\text {BET }} \\
\left(\mathrm{m}_{2} / \mathrm{g}\right)\end{array}$ & $\begin{array}{l}\mathrm{V}_{p} \\
\left(\mathrm{~cm}^{3} / \mathrm{g}\right)\end{array}$ & $\begin{array}{l}\phi_{p} \\
(\AA)\end{array}$ & $\% A l$ & $\begin{array}{l}\text { LAS } \\
(\mu \mathrm{mol} / \mathrm{g})\end{array}$ & $\begin{array}{l}\mathrm{BAS} \\
(\mu \mathrm{mol} / \mathrm{g})\end{array}$ & $\begin{array}{l}\mathrm{H}^{+} \\
(\mu \mathrm{mol} / \mathrm{g})\end{array}$ & $\begin{array}{l}\mathrm{r}_{0} \\
\left(\mu \mathrm{mol} / \mathrm{m}^{2} \mathrm{~h}\right)\end{array}$ \\
\hline SBA-15 & 860 & 1.141 & 53 & - & - & - & 34 & 28 \\
{$[$ Al]-SBA-15 (Si/Al = 114) } & 764 & 0.845 & 54 & 0.4 & 17 & 18 & 176 & 206 \\
[Al]-SBA-15 (Si/Al = 73) & 769 & 0.866 & 55 & 0.7 & 58 & 67 & 330 & 491 \\
[Al]-SBA-15 (Si/Al = 23) & 894 & 1.307 & 63 & 2.1 & 93 & 74 & 390 & 730 \\
\hline
\end{tabular}

The siliceous SBA-15 mesoporous sample showed short rod-like aggregates when examined by FE-SEM (Fig. S3a). The addition of $\mathrm{Al}$ into the SBA-15 resulted in a change in the particle's morphology, which became rounder as the content of Al increases (Fig. S3b-c), leading to platelet particles for [Al]SBA-15 (Si/Al = 23) sample (Fig. S3d).

The formation of honeycomb-like hexagonal arrangement of cylindrical pores is shown in the TEM images (Fig. S4), in agreement with previous results, revealing an effective synthesis of the mesoporous molecular sieves catalysts at all $\mathrm{Al}$ contents.

Structural short-range order of the T-O-T framework was evaluated by FTIR (Fig. S5). Asymmetrical stretching vibrations of $\mathrm{TO}$ and $\mathrm{TO}_{4}$ units $(\mathrm{T}=\mathrm{Si}, \mathrm{Al})$ were observed at around 1094 and $1222 \mathrm{~cm}^{-1}$, respectively, whilst the corresponding symmetrical stretching modes are seen at $800 \mathrm{~cm}^{-1} .9,57$ It was clear that the increase in the amount of $\mathrm{Al}$ in the structure shifts the absorption band at $1094 \mathrm{~cm}^{-1}$ to $1079 \mathrm{~cm}^{-1}$. Such a trend is associated with the changes in the T-O-T bonds, particularly the relaxation on the vibration of such bonds due to the substitution of $\mathrm{Al}$ into the structure of the silica framework. Tetrahedral bending modes of Si-O-Si and Si-O-Al were also seen at around $464 \mathrm{~cm}^{-1}$ and consequently a minor relaxation is also observed. In addition, surface silanol groups $(\mathrm{Si}-\mathrm{OH})$ were also shown by the band at $935 \mathrm{~cm}^{-1} .9$

Si local organization was assessed by ${ }^{29} \mathrm{Si}-\mathrm{NMR}$ and the spectra exhibited the presence of different silicon atom environments (Fig. S6a). Narrow and well resolved $Q_{2}$ $\left(\mathrm{Si}(\mathrm{OSi})_{2}(\mathrm{OH})_{2}\right)$ and $\mathrm{Q}_{3}\left(\mathrm{Si}(\mathrm{OSi})_{2}(\mathrm{OAI})(\mathrm{OH})\right)$ siloxane species were observed at -90 and -100 ppm while broad and poorly resolved $\mathrm{Q}_{4}$ sites which is associated with non-substituted siloxanes $\left(\mathrm{Si}(\mathrm{OSi})_{4}\right)$ were also observed at $-110 \mathrm{ppm}$.

For the samples generated by isomorphic substitution of $\mathrm{Si}$ by $\mathrm{Al}$ in the framework, ${ }^{27} \mathrm{Al}-\mathrm{NMR}$ spectra were also collected (Fig. 1). Tetrahedral sites in $\mathrm{AlO}_{4}$ structure unit and a minor presence of octahedral Al species (six-coordinate Al) were observed in all spectra at 54 and $0 \mathrm{ppm}$, respectively. ${ }^{58,59}$ These findings confirm that $\mathrm{Al}$ is found as a heteroatom in the framework associated with the amorphous cell walls of the mesoporous SBA-15 molecular sieves catalysts.

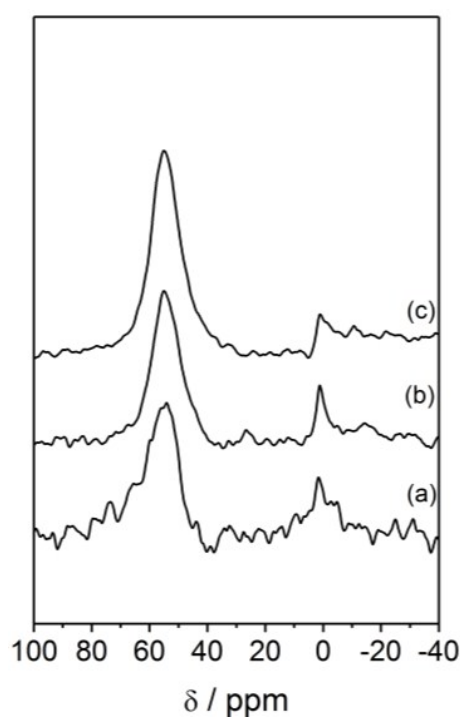

Fig. 1. 27Al (B) CP-NMR spectra of the synthesized mesoporous catalysts: (a) $[\mathrm{Al}]-\mathrm{SBA}-15$ (Si/Al = 23), (b) [AI]-SBA-15 (Si/Al = 73), (c) [Al]-SBA-15 (Si/Al = 114), (d) SBA-15.

Since acidity is expected to be generated by isomorphic substitution of Al, pyridine was taken as a probe molecule and its adsorption on the catalysts was monitored by infrared spectroscopy. The spectra displayed in Fig. 2 show absorption bands at $1454 \mathrm{~cm}^{-1}, 1489 \mathrm{~cm}^{-1}, 1594 \mathrm{~cm}^{-1}$ and $1621 \mathrm{~cm}^{-1}$ assigned to pyridine coordinated to Lewis acid sites while those at $1489 \mathrm{~cm}^{-1}, 1542 \mathrm{~cm}^{-1}$ and $1637 \mathrm{~cm}^{-1}$ are related to the pyridinium ion bonded to the Brønsted sites. This pattern indicates that both Lewis and Brønsted acidity were generated on the modified [AI]-SBA-15 since no acid site-related bands were seen on the bare unmodified SBA-15 spectra with only those related to pyridine $\mathrm{H}$-bonded to very weakly acidic hydroxyls observed (Fig. S7). The genesis of the Brønsted acid sites is well known to be related to Al occupying tetrahedral position into silica framework as observed by the NMR analyses (Fig. 1). Indeed, the higher the amount of Al in the framework the higher the concentration of both Lewis and Brønsted acid sites (Table 1). 


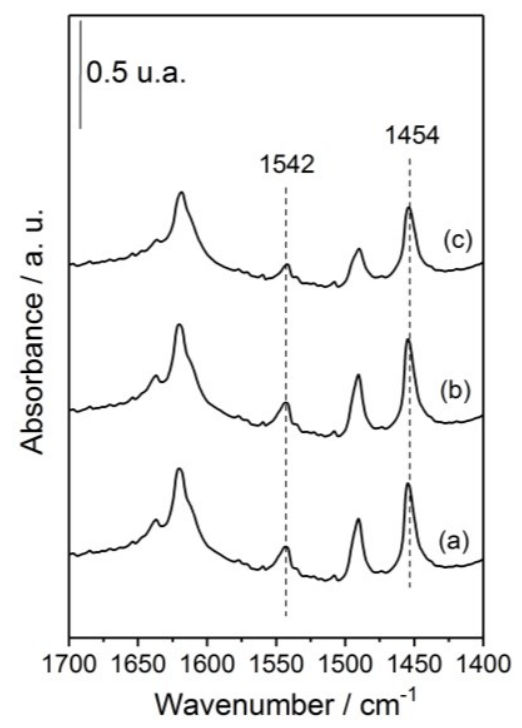

Fig. 2. FTIR spectra of adsorbed pyridine on $[\mathrm{Al}]-\mathrm{SBA}-15(\mathrm{Si} / \mathrm{Al}=23$ ) at (a) $150^{\circ} \mathrm{C}$, (b) $250^{\circ} \mathrm{C}$, (c) $350^{\circ} \mathrm{C}$.

Following the vibrations characterizing the $v 19 \mathrm{~b}$ mode of coordinated $\left(1454 \mathrm{~cm}^{-1}\right)$ and protonated $\left(1542 \mathrm{~cm}^{-1}\right)$ pyridine along with the desorption temperature, the acid strength could be assessed. Those bands were still clearly seen in the spectra at all temperatures up to $350{ }^{\circ} \mathrm{C}$ with only a small progressive decrease in intensity with temperature. This finding indicates the occurrence of significant concentrations of moderate to strong Lewis and Brønsted acid centres, which is consistent with the introduction of aluminum into mesoporous silica network.

As the intended catalytic application of such mesoporous catalysts is for aqueous-phase processing of monosaccharides, the total acidity was also determined by titration and results are summarised in Table 1. A substantial difference is observed comparing the pure SBA-15 with the modified [AI]-SBA-15 samples, which is in agreement with the pyridine adsorption experiments. The titration data also indicated that the acidity increases as the $\mathrm{Si} / \mathrm{Al}$ ratio decreases over the studied range, as expected.

All samples were tested for xylose aqueous-phase upgrading under mass-transfer free conditions. Reaction temperature was kept at $130{ }^{\circ} \mathrm{C}$ to avoid any thermal homogeneous conversion of xylose, which was found to occur from $150{ }^{\circ} \mathrm{C}$. Table 1 also summarizes the catalytic performance data of all the mesoporous catalysts while the time-resolved pentose conversion curves are presented in Fig. 3.
No activity was seen for the unmodified SBA 15 Awith the

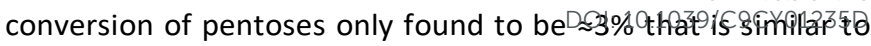
the control experiment with no catalyst. This result is in agreement with the low acidity of the siliceous SBA-15 framework.

Modifying the original inactive silica network with $\mathrm{Al}$, even with the lowest amount $([\mathrm{Al}]-\mathrm{SBA}-15(\mathrm{Si} / \mathrm{Al}=114))$, promoted the reaction with significant pentose conversion found for all samples (Fig. 3). The initial reaction rate has been normalised with respect to the catalyst surface area. The activity was found to steadily increase with increasing the content of Al. For example, the area normalised initial reaction rate $\left(r_{0}\right)$ was more than three times faster when going from Si/Al = 114 to 23 (Table 1). This behaviour can be related to the tuned acidity of the catalysts surface. ${ }^{28}$

The modifications to the surface of the [AI]-SBA-15 also dictated the product distribution. As shown in Fig. 4, furfuryl alcohol was the main product as calculated on the pentose basis (xylose+xylulose), and only a minor formation of furfural was found regardless the $\mathrm{Si} / \mathrm{Al}$ ratio. Nonetheless, when xylulose is considered as a product, i.e. selectivity is calculated on xylose basis only, the effect of Al introduction into the silica framework is more evident as depicted in Fig. S8. Indeed, xylulose, the keto isomer form of xylose, was rapidly formed during all catalytic runs and the time-dependent profiles (Fig. S8) indicated that this is an intermediate in the reaction of xylose to furanic compounds. This isomerisation reaction is reported to be the first reaction step, which readily takes place on the catalyst Lewis acid sites. ${ }^{22,23,60}$



Fig. 3. Time-resolved pentoses conversion curves on synthesized mesoporous catalysts: ( $\square)$ SBA-15, (O) [Al]-SBA-15 (Si/Al = 114), $(\triangle)$ [Al]-SBA-15 (Si/Al = 73), (ロ) [Al]-SBA-15 (Si/Al = 23). Reaction conditions: $130{ }^{\circ} \mathrm{C}, 30$ bar $\left(\mathrm{N}_{2}\right)$, water:2-propanol 1:1, xylose solution at $83 \mathrm{mmol} \mathrm{L}^{-1}$. 
All the modified [Al]-SBA-15 catalysts were highly selective to furfuryl alcohol reaching selectivities of between $90-95 \%$ within the whole range of pentose (xylose+xylulose) conversion as depicted in Fig. 4. This selectivity level lays within $40-90 \%$ when xylulose is also taken as a reaction product and only xylose conversion is considered (Fig. S8). This significant result is comparable to that recently reported on BEA zeolitic catalyst $(\mathrm{Si} / \mathrm{Al}=11)$ under the same reaction conditions. ${ }^{45}$ It reveals that both Lewis and Brønsted acid sites on [AI]-SBA-15 catalysts identified by pyridine-adsorbed infrared spectra are active and playing a role in the pentose tandem transformation. The production of furfuryl alcohol may, therefore, be explained by the tandem reaction of xylose/xylulose dehydration to furfural, which depends predominantly on Brønsted acidity, ${ }^{12,60,61}$ while the next cascade step (furfural transfer hydrogenation) occurs on the Lewis acid sites. ${ }^{44,45,62,63}$ This is consistent with the formation of propanone which was observed throughout the experiments using all modified catalysts, as depicted in Fig. S9, which is formed by the oxidation of 2-propanol via a Meerwein-Ponndorf-Verley (MPV) reaction. The surface sites involved in each reaction step is pointed out in Scheme 1.

The vital role played by 2-propanol as $\mathrm{H}$-donor in the mechanism of furfuryl alcohol formation was also evidenced by running a control experiment in the absence of a sacrificial alcohol. Fig. 5 contrasts the performance of [Al]-SBA-15 (Si/Al $=23$ ) in the aqueous-phase conversion of xylose with and without 2-propanol in the reaction medium. It is well demonstrated that reaction does not occur without a $\mathrm{H}$-donor as the conversion curve is equivalent of those collected without any catalyst or when siliceous SBA-15 is used as catalyst.

The vicinity of Brønsted and Lewis acid sites is suggested to be a major concern in these systems since the adsorbed furfural species can be reduced to furfuryl alcohol without being desorbed. This process may explain the low selectivity to furfural observed herein. To support this proposal, furfural was used as the substrate and the reaction was performed under

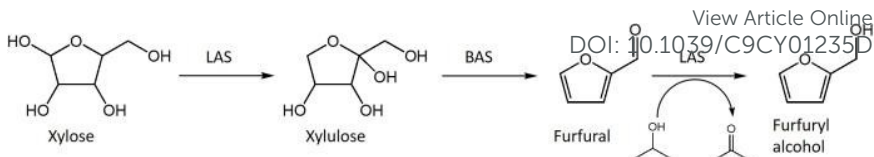

Scheme 1. Simplified scheme of xylose conversion into furfuryl alcohol.

the same conditions used in this study. No activity or furfuryl alcohol formation were observed over any of the studied catalysts. This indicates that the transfer hydrogenation of free furfural molecules to furfuryl alcohol on [AI]-SBA-15 catalysts would require much higher temperatures, as has been used for

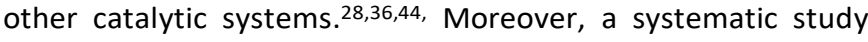
reported on furfural reduction via the MPV mechanism clearly demonstrated that the presence of water in the reaction medium hinders the catalytic activity. ${ }^{36}$ It should be recalled that, in contrast with other studies on the direct conversion of xylose to green chemicals, $29,44,46$ the experiments reported, herein, were conducted in an aqueous-phase (water:2propanol 1:1) since the one-pot tandem catalytic conversion of xylose was the desired reaction which was required to dissolve the monosaccharide. Therefore a lower activity should be expected when compared to other studies based on organic solvents. ${ }^{29,44,46}$ This damaging effect of water has been associated with the interaction between water molecules from the reaction medium and/or produced upon reaction with the surface acid sites. ${ }^{45,64-66}$ As a consequence, the water molecules may be kept attached to the acid centres decreasing its intrinsic activity. Such detrimental effect of water was previously evidenced by performing the reaction at different water:2-propanol mixture compositions. ${ }^{45}$ Large amounts of water was shown to significantly decrease the catalytic activity even for a more hydrophobic catalyst surface. ${ }^{45}$
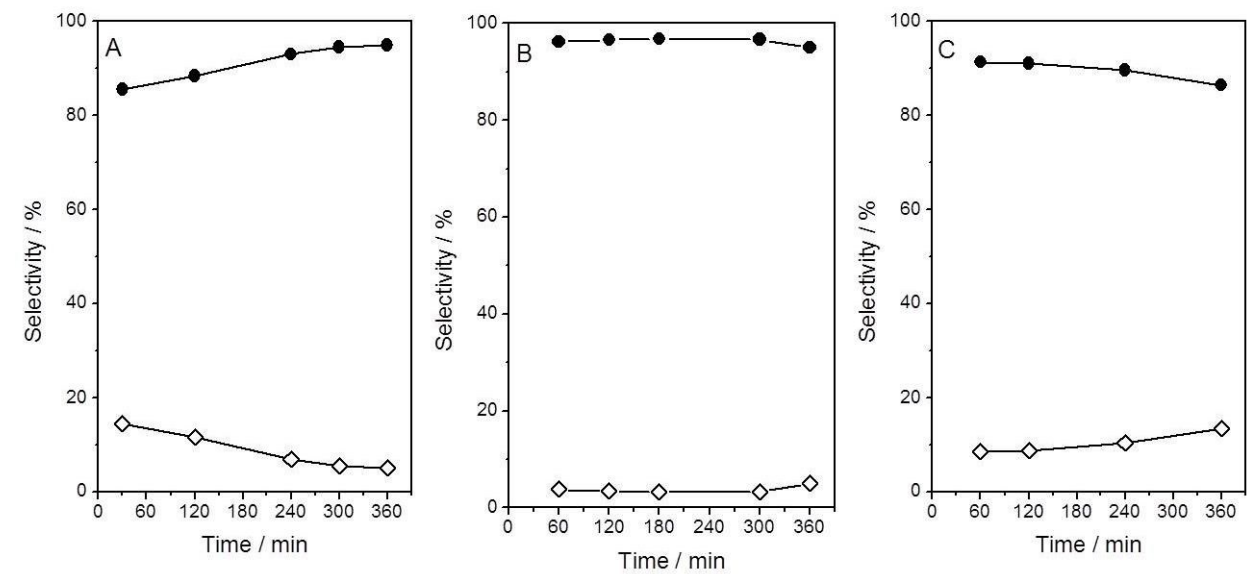

Fig. 4. Selectivities to furfuryl alcohol $(\bullet)$ and furfural $(\diamond)$ as a function of pentose conversion on synthesized mesoporous catalysts. Reaction conditions: $130^{\circ} \mathrm{C}, 30$ bar $\left(\mathrm{N}_{2}\right)$, water:2-propanol 1:1, xylose solution at $83 \mathrm{mmol} \mathrm{L}^{-1}$. 


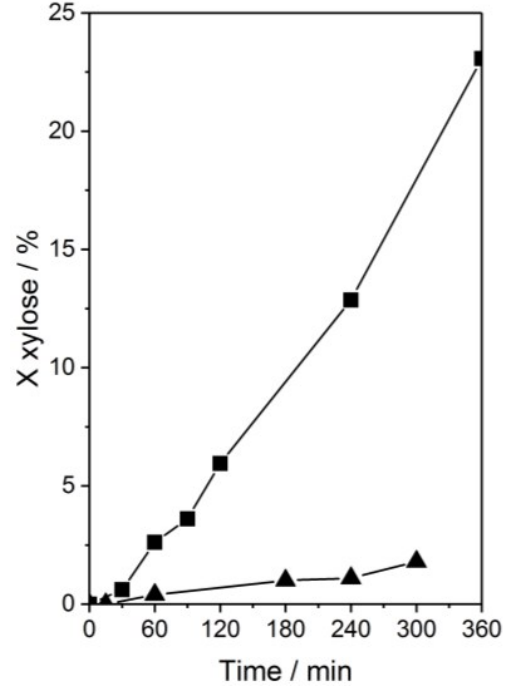

Fig. 5. Time-resolved pentoses conversion curves on [AI]-SBA-15 $(\mathrm{Si} / \mathrm{Al}=23)$ in water $(\boldsymbol{A})$ and water:2-propanol 1:1 ( $\boldsymbol{\square})$. Reaction conditions: $130{ }^{\circ} \mathrm{C}, 30$ bar $\left(\mathrm{N}_{2}\right)$, xylose solution at $83 \mathrm{mmol} \mathrm{L}^{-1}$.

A good carbon balance ranging from 92 to $105 \%$ was observed and this was maintained during the reactions. It is worth noting that neither retro-aldol condensation and etherification products nor acetals were formed in any experiment. It could be due to the inappropriate acidity strength, concentration of acid sites or the short reaction time and low reaction temperature, which were chosen to keep low conversion conditions.

To evaluate the catalyst performance at different pentose (xylose+xylulose) conversions, additional runs were carried out at distinct reaction conditions using $[\mathrm{Al}]-\mathrm{SBA}-15 \quad(\mathrm{Si} / \mathrm{Al}=23$ ) and the results are collected in Table 2. Raising pentose conversion up to $\sim 40 \%$ by increasing the amount of catalyst (Table 2, entry 2 ) or reaction time (Table 2 , entry 4 ), selectivity to furfuryl alcohol dropped to $50-60 \%$ but it is still the major reaction product. Pushing pentose conversion to $\sim 70 \%$ by increasing reaction temperature (Table 2 , entry 3 ) led to a more severe drop in furfuryl alcohol selectivity. It should be noted that carbon balance also decreased significantly, reaching $54 \%$ under this condition (Table 2, entry 3 ). These data indicate that working at higher temperature leads to the formation of heavy compounds mostly likely derived from polymerization and condensation reactions. Data referring to xylose conversion only, i.e. when xylulose is also taken as a reaction product, are summarized in Table S1.

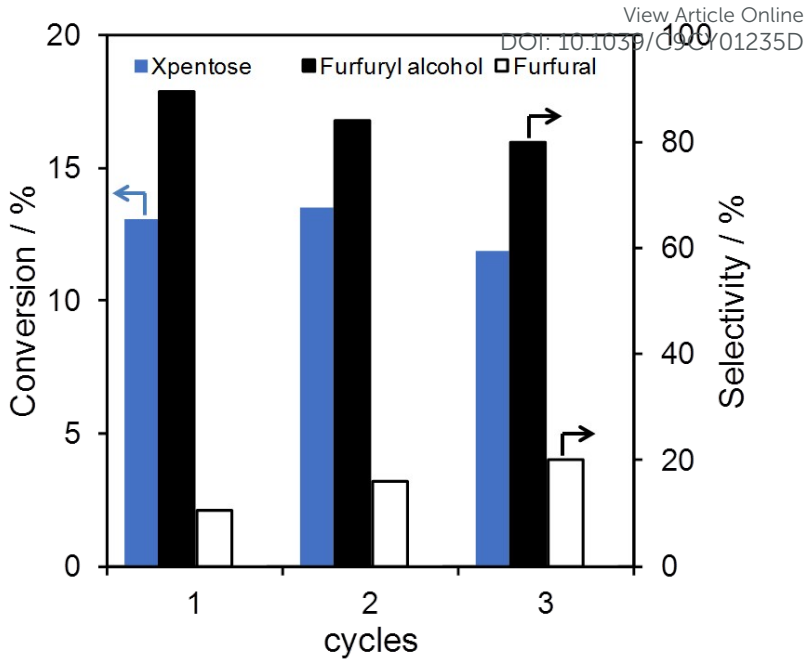

Fig. 6. Pentose conversion $\left(X_{\text {pentose }}\right)$ and selectivities to furfuryl alcohol and furfural for three consecutive reaction cycles performed with [Al]-SBA-15 (Si/Al = 23). Reaction conditions: $130{ }^{\circ} \mathrm{C}$, 30 bar $\left(\mathrm{N}_{2}\right)$, water:2-propanol $1: 1$, xylose solution at $83 \mathrm{mmolL}^{-1}$.

In order to test the recyclability, the $[\mathrm{Al}]-\mathrm{SBA}-15$ (Si/Al = 23) catalyst was recovered by filtration following reaction, dried and used in consecutive catalytic runs. Fig. 6 shows pentose (xylose+xylulose) conversion and product selectivities for three reaction cycles after $4 \mathrm{~h}$ of reaction. The pentose conversion was around $15 \%$ in all runs indicating little loss in activity. The selectivity to furfuryl alcohol showed a minor decrease from 90 to $80 \%$. In contrast, the formation of furfural gradually increased from 10 to $20 \%$ over the three cycles. This trend might indicate that the Lewis acid sites associated with the MPV reduction become less active after each run, which would result in lower conversions of the adsorbed furfural intermediate allowing the aldehyde to desorb.

Following the reactions, the structural stability of [AI]-SBA$15(\mathrm{Si} / \mathrm{Al}=23)$ sample was analysed by SAXRD, TEM and ${ }^{27} \mathrm{Al}-$ NMR and the results are presented in Fig. 7.

Table 2. Reaction temperature $(T)$, catalyst amount $\left(m_{\text {cat }}\right)$, total reaction time $(t)$, pentose conversion $\left(X_{\text {pentose }}\right)$, selectivity to furfuryl alcohol $\left(\mathrm{S}_{\mathrm{FFA}}\right)$ and furfural $\left(\mathrm{S}_{\mathrm{FF}}\right)$, carbon balance and catalyst aluminium content (\%Al) after reaction using [AI]-SBA-15 $(\mathrm{Si} / \mathrm{Al}=23)$.

\begin{tabular}{lllllllll}
\hline Entry & $\mathrm{T}\left({ }^{\circ} \mathrm{C}\right)$ & $\mathrm{m}_{\text {cat }}(\mathrm{g})$ & $\mathrm{t}(\mathrm{h})$ & $\mathrm{X}_{\text {pentose }}(\%)$ & $\mathrm{S}_{\mathrm{FFA}}(\%)$ & $\mathrm{S}_{\mathrm{FF}}(\%)$ & $\mathrm{CB}(\%)$ & $\% \mathrm{Al}$ \\
\hline 1 & 130 & 0.25 & 6 & 19 & 53 & 6 & 92 & 2.3 \\
2 & 130 & 0.50 & 6 & 22 & 61 & 8 & 93 & 2.3 \\
3 & 150 & 0.25 & 6 & 67 & 20 & 12 & 54 & 2.3 \\
4 & 130 & 0.25 & 24 & 39 & 50 & 15 & 86 & 2.1 \\
\hline
\end{tabular}




\section{ARTICLE}
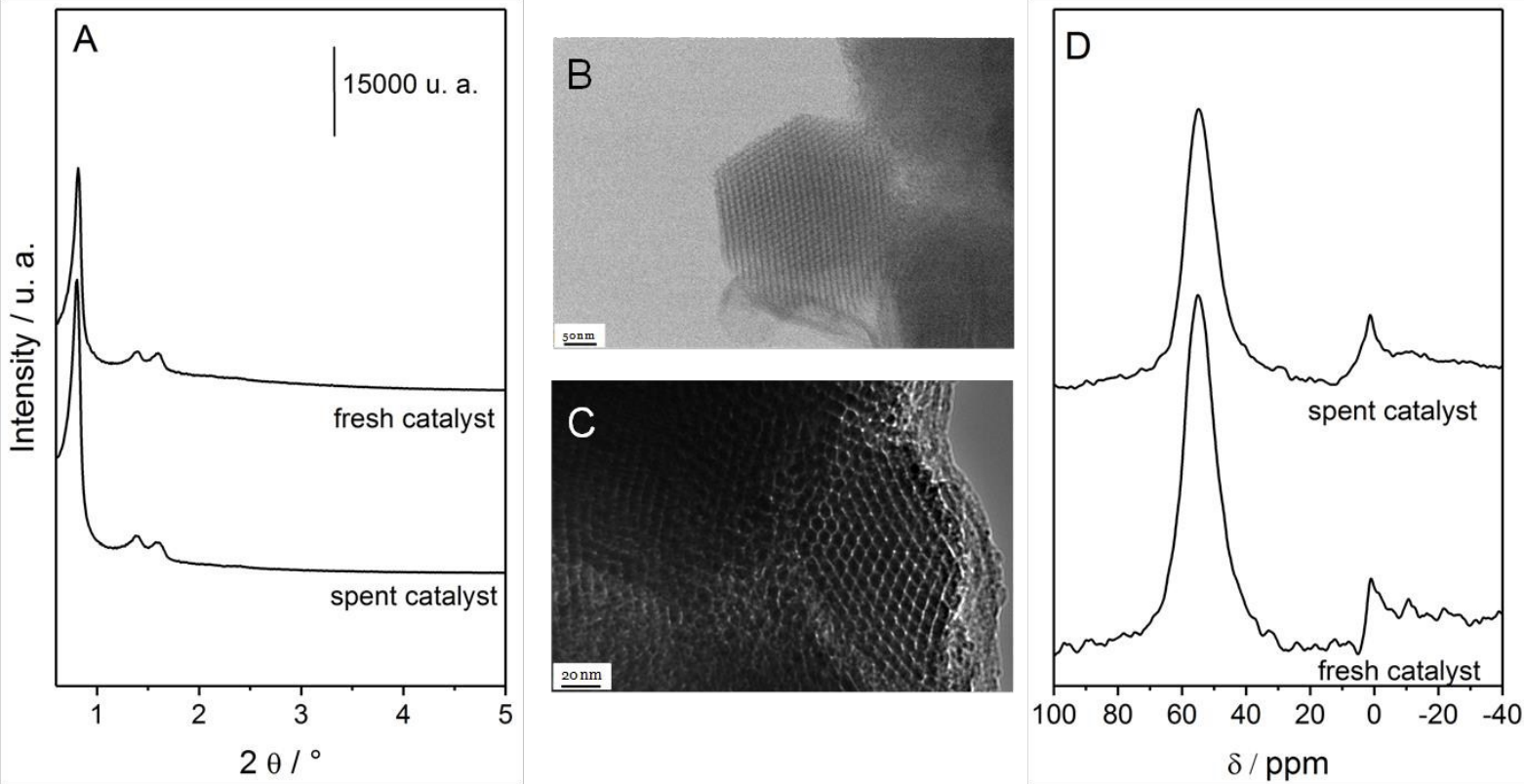

Fig. 7. (A) Small angle diffractogram of fresh and spent [Al]-SBA-15 (Si/Al =23), (B) and (C) TEM image of spent [Al]-SBA-15 $(\mathrm{Si} / \mathrm{Al}=23),(\mathrm{D}){ }^{27} \mathrm{Al} \mathrm{CP}-\mathrm{NMR}$ spectra of fresh and spent $[\mathrm{Al}]-\mathrm{SBA}-15(\mathrm{Si} / \mathrm{Al}=23)$.

SAXRD shows that the catalyst mesostructure is preserved intact when compared to the fresh sample (Fig. 7a). The structure was also found to be stable by the TEM showing no change in the honeycomb-like hexagonal arrangement of cylindrical pores as depicted in the two different magnification images of the spent catalyst in Fig. 7b (compare with those in Fig. S4). ${ }^{27} \mathrm{Al}-\mathrm{NMR}$ spectrum of the spent catalyst (Fig. 7c) also showed similar amounts of tetrahedral sites in the $\mathrm{AlO}_{4}$ structure unit and octahedral Al species (six-coordinate Al) as found for the fresh sample.

Regarding the chemical stability, ICP-OES analyses of both fresh (Table 1) and spent (Table 2) catalyst showed that they present the same content of $\mathrm{Al}$, indicating that no leaching occurs during reaction under the conditions applied. Accordingly, no Al was detected in the aqueous reaction solution.

\section{Conclusions}

Pentose sugars were converted to furfuryl alcohol by tandem reactions over metal-free mesoporous catalysts with SBA-15 topology. Brønsted acid sites generated by introducing Al into the siliceous SBA-15 framework were found to be active for the pentose dehydration reaction, whilst Lewis acid sites promoted the transfer hydrogenation of adsorbed furfural intermediate to furfuryl alcohol. A high selectivity to furfuryl alcohol $(90-95 \%)$ was observed on the mesoporous catalysts and it was dependent of the Al concentration in the siliceous framework. More importantly, these [AI]-SBA-15 molecular sieve catalysts were shown to be chemically and structurally stable. Therefore, these engineered [AI]-SBA-15 catalysts have been shown to be effective in an environment-friendly green process for the aqueous-phase processing of biomass-derived monossaccharides. In these systems neither molecular hydrogen nor noble metal sites are required for xylose upgrading. The use of mesoporous materials also offers the opportunity to expand the range of biomass-derived products that can be converted.

\section{Conflicts of interest}

There are no conflicts to declare.

\section{Acknowledgements}

The authors are thankful to Prof. Heloise O. Pastore (UNICAMP, Brazil) for her assistance with the ${ }^{29} \mathrm{Si}$ and ${ }^{27} \mathrm{Al} \mathrm{CP}$ NMR analyses and Dr. Tiago L. Coelho (INT, Brazil) for the quantitative FTIR-Py measurements. Authors are also indebted 
to LabNano/CBPF (Brazil) and CENANO/INT (Brazil) for TEM and FE-SEM examinations. Financial support from CNPq and CAPES (PDSE 88881.132754/2016-01) (Brazil) is also acknowledged.

\section{References}

1 A. S. Mamman, J. Lee, Y. Kim, I. T. Hwang, N. Park, Y. K. Hwang, J. Chang and J. Hwang, Biofuels, Bioprod. Bioref. 2008, 2, 438

2 S. G. Wettstein, D. M. Alonso, E. I Gürbüz and J. A. Dumesic, Curr. Opin. Chem. Eng., 2012, 1, 218.

3 J. Lange, E. Heide, J. Buijtenen and R. Price, ChemSusChem., 2012, 5, 150-166.

4 X. Shi, Y. Wu, H. Yi, G. Rui, P. Li, M. Yang and G. Wang, Energies, 2011, 4, 669.

5 M. M. Antunes, S. Lima, A. Fernandes, J. Candeias, M. Pillinger, S. M. Rocha, M. F. Ribeiro and A. A. Valente, Catal. Today, 2012, 195, 127.

6 S. Dutta, S. De, B. Saha and I. Alam, Catal. Sci. Technol., 2012, 2, 2025.

7 R. Weingarten, G. A. Tompsett, W. C. Conner Jr. and G. W. Huber, J. Catal., 2011, 279, 174.

8 R. Weingarten, G. A. Tompsett, W. C. Conner Jr. and G. W. Huber, J. Catal., 2011, 279, 174.

9 M. J. C. Molina, M. L. Granados, A. Gervasini, Catal. Today, 2015, 254, 90.

10 J. Iglesias, J. A. Melero, G. Morales, M. Paniagua, B. Hernández, Chem CatChem, 2016, 8, 2089.

11 C. Sener, A. H. Motagamwala, D. M. Alonso, J. A. Dumesic, ChemSusChem, 2018, 11, 2321.

12 C. Moreno-Marrodan, P. Barbaro, S. Caporali, F. Bossola, ChemSusChem, 2018, 11, 3649.

13 J. Lee, Y. Xu and G. W. Huber, Appl. Catal. B-Environ., 2013, 140-141, 98.

14 D. Liu, D. Zemlyanov, T. Wu, R. J. Lobo-Lapidus, J. A. Dumesic, J. T. Miller and C. L. Marshall, J. Catal., 2013, 299, 336.

15 J. Lange, W. D. van de Graaf and R. J. Haan, ChemSusChem, 2009, 2, 437

16 M. J. Taylor, L. J. Durndell, M. A. Isaacs, C. M. A. Parlett, K. Wilson, A. F. Lee, G. Kyriakou, Appl. Catal. B-Environ., 2016, $180,580$.

17 X. Chen, L. Zhang, B. Zhang, X. Guo, X. Mu, Sci. Rep., 2016, 6 28558.

18 O. F. Aldosari, S. Iqbal, P. J. Miedziak, G. L. Brett, D. R. Jones, X. Liu, J. K. Edwards, D. J. Morgan, D. K. Knight, G. J. Hutching, Catal. Sci. Technol., 2016, 6, 234.

19 C. Nguyen-Huy, J. S. Kim, S. Yoon, E. Yang, J. H. Kwak, M. S. Lee, K. An, Fuel, 2018, 226, 607.

20 J. Cui, J. Tan, X. Cui, Y. Zhu, T. Deng, G. Ding and Y. Li, ChemSusChem, 2016, 9, 1.

21 R. F. Perez and M. A. Fraga, Green Chem., 2014, 16, 3942.

22 R. F. Perez, S. J. Canhaci, L. E. P. Borges and M. A. Fraga, Catal. Today, 2017, 289, 273.

23 S. J. Canhaci, R. F. Perez, L. E. P. Borges and M. A. Fraga, Appl. Catal. B-Environ., 2017, 207, 279.

24 Y. He, Y. Ding, C. Ma, J. Di, C. Jiang and A. Li, Green Chem., 2017, 19, 3844.

25 C. F. de Graauw, J. A. Peters, H. van Bekkum and J. Huskens, Synthesis, 1994, 10, 1007.

26 Z. K. Gao, Y. C. Hong, Z. Hu and B. Q. Xu, Catal. Sci. Technol., 2017, 7, 4511.

27 J. Iglesias, J. A. Melero, G. Morales, M. Paniagua, B. Hernández, A. Osatiashtiani, A. F. Lee and K. Wilson, Catal. Sci. Technol., 2018, 8, 4485.

28 J. Zhang, K. Dong, W. Luo and H. Guan, ACS Omega, 2018, 3, 6206.
29 J. A. Melero, G. Morales, J. Iglesias, M. Paniagua, C. LópezAguado, K. Wilson and A. OsatiashtianioGree03Ghemr,02035, 19, 5114.

30 S. Song, L. Di, G. Wu, W. Dai, N. Guan and L. Li, Appl. Catal. BEnviron., 2017, 205, 393.

31 W. B. Gong, C. Chen, Y. Zhang, H. J. Zhou, H. M. Wang, H. M. Zhang, Y. X. Zhang, G. Z. Wang and H. J. Zhao, ACS Sustain. Chem. Eng., 2017, 5, 2172.

32 L. Bui, H. Luo, W. R. Gunther and Y. Roman-Leshkov, Angew. Chem., 2013, 52, 8022.

33 M. Koehle and R. F. Lobo, Catal. Sci. Technol., 2016, 6, 3018.

34 M. M. Antunes, S. Lima, P. Neves, A. L. Magalhães, E. Fazio, F. Neri, M. T. Pereira, A. F. Silva, C. M. Silva, S. M. Rocha, M. Pillinger, A. Urakawa and A. A. Valente, Appl. Catal. BEnviron., 2016, 182, 485.

35 M. M. Antunes, S. Lima, P. Neves, A. L. Magalhães, E. Fazio, A. Fernandes, F. Neri, C. M. Silva, S. M. Rocha, M. F.Ribeiro, M. Pillinger, A. Urakawa and A. A. Valente, J. Catal., 2015, 329, 522.

36 R. López-Asensio, J. A. Cecilia, C. P. Jiménez-Gómez, C. García-Sancho, R. Moreno-Tost, P. Maireles-Torres, Appl. Catal. A-Gen., 2018, 556, 1.

37 J. Jae, E. Mahmoud, R. F. Lobo and D. G. Vlachos, ChemCatChem, 2014, 6, 508.

38 W. Hao, W. Li, X. Tang, X. Zang, Y. Sun, S. Liu and L. Liin, Green Chem., 2016, 18, 1080.

39 J. Wei, X. Cao, T. Wang, H. Liu, X. Tang, X. Zeng, Y. Sun, T. Lei, S. Liu and L. Lin, Catal. Sci. Technol., 2018, 8, 4474.

40 Y. Kuwahara, W. Kaburagi, Y. Osada, T. Fujitani and H. Yamashita, Catal. Today, 2017, 281, 418.

41 X. Tang, L. Hu, Y. Sun, G. Zhao, W. W. Hao and L. Lin, RSC Adv. 2013, 3, 10277.

42 J. L. Song, L. Q. Wu, B. W. Zhou, H. C. Zhou, H. L. Fan, Y. Y. Yang, Q. L. Meng and B. X. Han, Green Chem., 2015, 17, 1626.

43 M. Chia and J. A. Dumesic, Chem. Commun., 2011, 47, 12233.

44 B. Hernández, J. Iglesias, G. Morales, M. Paniagua, C. LópesAguado, J. L. G. Fierro, P. Wolf, I. Hermans and J. A. Melero, Green Chem., 2016, 18, 5777.

45 P. N. Paulino, R. F. Perez, N. G. Figueiredo and M. A. Fraga, Green Chem., 2017, 19, 3759.

46 C. López-Aguado, M. Paniagua, J. Iglesias, G. Morales, J. L. G. Fierro and J. A. Melero, Catal. Today, 2018, 304, 80.

47 S. Zhu, Y. Xue, J. Guo, Y. Gen, J. Wang and W. Fan, ACS Catal., 2016, 6, 2035.

48 J. Iglesias, J. A. Melero, G. Morales, J. Moreno, Y. Segura, M. Paniagua, A. Cambra and B. Hernández, Catalysts, 2015, 5, 1911.

49 D. Zhao, J. Feng, Q. Huo, N. Melosh, G. H. Fredrickson, B. F. Chmelka and G. D. Stucky, Science, 1998, 279, 548.

50 F. S. Ramos, A. M. Duarte de Farias, L. E. P. Borges, J. L. Monteiro, M. A. Fraga, E. F. Sousa-Aguiar and L. G. Appel, Catal. Today, 2005, 101, 39.

51 S. E. Davis, A. D. Benavidez, R. W. Gosselink, J. H. Bitter, K. P. de Jong, A. K. Datye and R. J. Davis, J. Mol. Catal. A-Chem., 2014, 388-389, 123.

52 M. Thommes, K. Kaneko, A. V. Neimark, J. P. Olivier, F. Rodriguez-Reinoso, J. Rouquerol and K. S. W. Sing, Pure Appl. Chem., 2015, 87, 1051.

53 T. Benamor, L. Vidal, B. Lebeau and C. Marichal, Micropor. Mesopor. Mat., 2012, 153, 100.

54 S. Handjani, E. Marceau, J. Blanchard, J. Krafft, M. Che, P. Mäki-Arvela, N. Kumar, J. Wärnå and D. Y. Murzin, J. Catal., 2011, 282, 228.

55 J. M. R. Gallo, C. Bisio, G. Gatti, L. Marchese and H. O. Pastore, Langmuir, 2010, 26, 5791.

56 N. Lucas, G. Kokate, A. Nagpure and S. Chilukuri, Micropor. Mesopor. Mat., 2013, 181, 38. 
57 Z. Luan and J. A. Fournier, Micropor. Mesopor. Mat., 2005, 79, 235.

58 P. Shah, A. V. Ramaswamy, K. Lazar and V. Ramaswamy, Micropor. Mesopor. Mat., 2007, 100, 210.

59 D. M. Do, S. Jaenicke and G. Chuah, Catal. Sci. Technol., 2012, 2, 1417.

60 V. Choudhary, S. I. Sandler and D. G. Vlachos, ACS Catal., 2012, 2, 2022.

61 V. Choudhary, A. B. Pinar, S. I. Sandler, D. G. Vlachos and R. F. Lobo, ACS Catal., 2011, 1, 1724.

62 A. Corma, M. E. Domine and S. Valencia, J. Catal., 2003, 215, 294.

63 F. Gonell, M. Boronat and A. Corma, Catal. Sci. Technol., 2017, 7, 2865.

64 D. Zhang, A. Duan, Z. Zhao, X. Wang, G. Jiang, J. Liu, C. Wang and M. Jin, Catal. Today, 2011, 175, 477.

65 C. X. A. da Silva, V. L. C. Gonçalves and C. J. Mota, Green Chem., 2009, 11, 38.

66 K. M. A. Santos, E. M. Albuquerque, G. Innocenti, L. E. P. Borges, C. Sievers and M. A. Fraga, ChemCatChem, 2019, 11, 3054. 
Aqueous-phase tandem catalytic conversion of xylose to furfuryl alcohol $)_{/ C 9 C Y 01235 \mathrm{D}}^{\mathrm{ew}}$

\section{over $[\mathrm{Al}]-\mathrm{SBA}-15$ molecular sieves}

Rafael F. Perez, ${ }^{a, b}$ Elise M. Albuquerque, ${ }^{b}$ Luiz E. P. Borges, ${ }^{a}$ Christopher Hardacre ${ }^{* c}$ and $\operatorname{Marco}$ A. Fraga ${ }^{* a, b}$

anstituto Militar de Engenharia, Praça Gen. Tibúrcio, 80, Urca, Rio de Janeiro/RJ, 22290270, Brazil.

' Instituto Nacional de Tecnologia/MCTIC, Laboratório de Catálise, Av. Venezuela, 82/518, Saúde, Rio de Janeiro/RJ, 20081-312, Brazil.

'School of Chemical Engineering and Analytical Science, The University of Manchester, The Mill, Sackville Street, Manchester M13 9PL, UK.

\section{Corresponding authors}

Marco A. Fraga.

E-mail: marco.fraga@int.gov.br. Phone: +55-21-2123-1152.

Christopher Hardacre

E-mail: c.hardacre@manchester.ac.uk

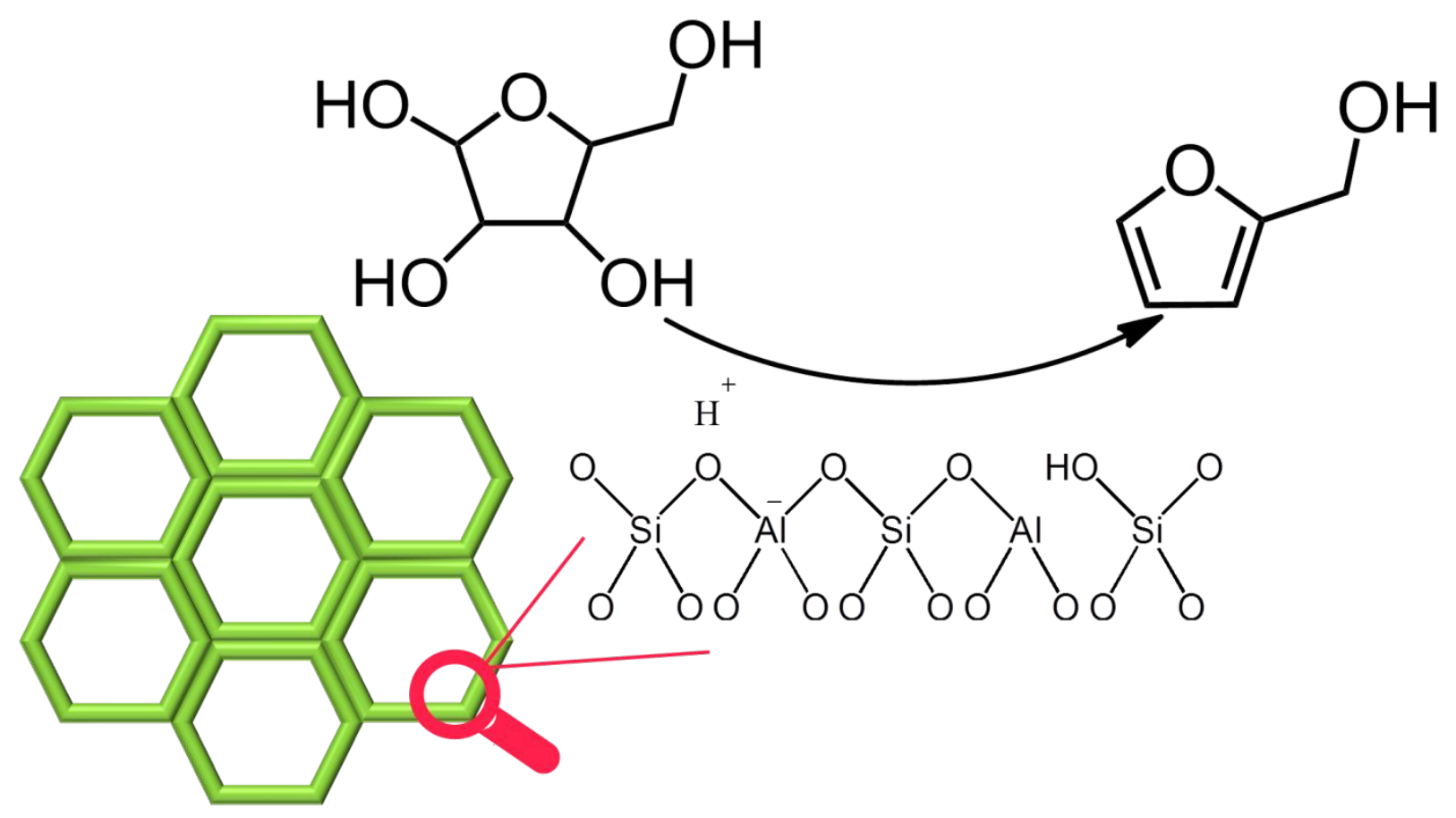

